\title{
ARQUEOLOGIA E ARQUITETURA: PROPOSTA DE REVITALIZAÇÃO DO PORTO DO RIBEIRA
}

O objetivo desta nota é divulgar o projeto de revitalização da área do antigo Porto do Ribeira, que está sendo desenvolvido através de um trabalho conjunto entre a Universidade de São Paulo, a Prefeitura de Iguape e a iniciativa privada. ${ }^{1}$

A proposta de revitalização do antigo Porto do Ribeira, visando devolver à cidade os marcos físicos da sua história, veio de encontro à preocupação da Prefeitura Municipal de Iguape de valorizar a entrada da cidade, localizada na antiga área portuária. Assim, o projeto original de acesso à cidade feito através de um pórtico, deu lugar à proposta mais ampla de revitalização e restauro da área. ${ }^{2}$

A idéia de revitalização partiu da evidenciação de elementos, arqueológicos e históricos, em uma região antropicamente descaracterizada.

A pesquisa arqueológica possibilitando a elaboração do projeto de revitalização da área, com a devolução à comunidade de um espaço urbano otimizado e com melhor qualidade, cumpre o seu papel social, fazendo com que os

(1) A pesquisa arqueológica neste local foi decorrente daquela realizada anteriormente no Porto Grande, no âmbito do Programa Arqueológico do baixo Vale do Ribeira, que vem sendo desenvolvido sob a coordenação da Profa. Dra. Maria Cristina Mineiro Scatamacchia e com o apoio financeiro da Fundação de Amparo à pesquisa do Estado de São Paulo-FAPESP.

O Porto do Ribeira, situado no rio do mesmo nome, e o Porto Grande, localizado nas margens do Mar Pequeno, eram articulados e faziam parte do sistema de escoamento dos produtos agrícolas do médio e alto Ribeira. No que se refere à iniciativa privada, dando corpo ao espírito lançado pelo art.199 da Constituição do Estado de São Paulo, as instituições públicas responsáveis pelo projeto, seguindo a melhor orientação de política pública para o caso, criaram condiçōes de ser articulada uma unidade privada de conservação. Estamos contando com toda a participação do escritório Burle Marx e Cia. Ltda.

(2) O projeto será executado com verba fornecida pelo DADE-Departamento de Apoio ao Desenvolvimento das Estâncias, da Secretária de Esportes e Turismo, do Governo do Estado de São Paulo. vestígios do passado sejam utilizados em benefício do presente.

A proposta final de revitalização é a implantação de um espaço museológico, que crie um marco forte na entrada e que ao mesmo tempo sirva de cartão de visita anunciando o caráter da cidade. Este espaço tem uma dupla função: de história e uso social. ${ }^{3}$ Consideramos a revitalização como uma solução eficaz para a conservação dos sítios arqueológicos históricos e para o processo de conscientização e valorização do patrimônio cultural. Este último constitui um dado fundamental em qualquer proposta de revitalização de áreas e edificações que necessitam de recuperação parcial e integral em decorrência do processo de deterioração sofrido.

A vocação que se pretende transmitir ao visitante está relacionada com os aspectos ecológico, histórico e arqueológico e paisagístico, presentes na entrada, onde estão representados pela densa vegetação, pela igreja e estruturas associadas ao antigo porto.

A realização deste trabalho significou a possibilidade da concretização de um projeto de política pública, dentro de uma abordagem multidisciplinar. ${ }^{4}$

A área a ser revitalizada corresponde atualmente ao primeiro bairro atingido pela estrada de acesso à cidade. No passado, a localidade englobava as construções e facilidades relacionadas ao funcionamento do antigo Porto do Ribeira, que era considerado em meados do século XIX um pitoresco povoado situado em um dos melhores locais

(3) Estamos defendendo para a região a idéia de uso social dos sítios arqueológicos como forma de conservação. Pensamos a revitalização da mesma maneira, isto é, para que uma área volte a ser valorizada, ela deve ter uma função, um uso social que garanta a sua manutenção e preservação.

(4) $\mathrm{Na}$ implantação do projeto estão envolvidas áreas públicas e particulares, a criação de um Centro Cultural e de uma Escola de Cantaria. 
da cidade, no trecho onde o rio Ribeira se aproxima do oceano, mais ou menos três quilômetros da cidade de Iguape.

As fontes de referência para a identificação da área do antigo Porto do Ribeira são constituídas por documentos textuais, iconográficos e materiais. Não existe documentação que nos remeta às origens do Porto do Ribeira, mas no século XVII já existia o povoado no local. Mas, é somente em meados do século XIX que o porto realmente passou a ter importância em função do desenvolvimento da produção de arroz e do aumento da circulação de mercadorias envolvendo os dois portos. Em 1833, o local já contava com mais de 40 casas, a capela de São João e um chafariz. A sua posição como ponto estratégico persistiu até a abertura e utilização do Valo Grande. ${ }^{5}$

Do ponto de vista da documentação material, várias estruturas de pedra e algumas construções constituem remanescentes das antigas atividades desenvolvidas no porto.

Mesmo após o assoreamento do Porto Grande, o local continuou a ser utilizado para o desembarque e armazenamento de mercadorias vindas do Ribeira acima. Em períodos recentes foram instaladas fábricas no local, últimos testemunhos das atividades realizadas na antiga área portuária que, cessando, levaram a área a um abandono.

As pesquisas arqueológicas recuperaram as estruturas arquitetônicas, de natureza variada, constituídas por alicerces, colunas e pisos que testemunham a dimensão e volume do movimento do antigo porto.

A pesquisa de arqueologia histórica ${ }^{6}$ realizada em conjunto com o estudo arquitetônico, representa um grande avanço para as

(5) A vontade de melhorar a ligação dos dois portos, com a abertura de um canal, precipitou o colapso econômico na região. Na verdade, a abertura do Valo não trouxe a melhoria esperada, ao contrário: as areias trazidas do rio Ribeira foram depositadas no Porto Grande, obstruindo e afastando o ancoradouro de barcos da cidade.

(6) Estamos considerando a arqueologia histórica como "o estudo dos aspectos materiais, em termos históricos, culturais e sociais concretos, dos efeitos do mercantilhismo e do capitalismo que foi trazido da Europa em fins do século XV e que continua em açāo ainda hoje (Orser Jr. 1992: 23). duas disciplinas, no conhecimento da aparência física, dos processos construtivos e do uso dos sítios. Essa dupla abordagem é necessária quando se pensa na restauração dos sítios, parcial ou total, visando dar a eles um uso social.

Um problema relevante na escavação e restauração de sítios históricos é aquele que se refere ao momento cronológico a ser considerado. No caso do Porto do Ribeira, o corte cronológico se refere a meados do século XIX.

$O$ significado do passado não é neutro e está relacionado com a maneira em que ele é interpretado e politicamente usado. No nosso caso, o passado que está sendo enfocado representa um momento de riqueza e abundância, que resultou na cultura material resgatada pela arqueologia, e faz com que a cidade se recorde de uma condição que foi perdida ao longo do tempo em consequiência de uma intervenção ambiental que ocasionou o fechamento dos portos.

A arqueologia atuou como meio de resgatar um marco histórico, que não pode ser isolado do seu aspecto ideológico, e que forneceu a base para reverter uma situação, revitalizando um espaço que correspondeu a um período de riqueza anterior, em substituição à marginalização do presente.

A estratégia de implantação do projeto se deu através de reuniões com os diferentes profissionais envolvidos, nas quais foram considerados problemas de diferente natureza. Dentro de uma abordagem interdisciplinar, as considerações teórico-metodológicas levaram em conta as especificídades das disciplinas envolvidas.

$\mathrm{O}$ projeto envolve áreas públicas ${ }^{7} \mathrm{e}$ particulares $^{8}$ e um terreno de marinha, onde se

(7) Além das áreas públicas da Prefeitura Municipal de Iguape, foram incorporados ao projeto os terrenos próximos ao Valo Grande pertencentes ao DAE, que os cedeu para a reurbanização do local.

(8) As áreas particulares relacionadas ao projeto são de diferente natureza. Os terrenos onde estão localizadas as estruturas do antigo Porto do Ribeira estão incorporados ao projeto harmonicamente, compondo um único conjunto. Paralelo a esta situação existem construções que deverão sofrer um processo de alteração na fachada para atender aos critérios mínimos de programação visual propostos pela comissão executora do projeto. 
instalou uma grande favela, ${ }^{9}$ sendo que cada uma destas parcelas sofreu abordagens diferenciadas.

No que se refere ao conceito de revitalização de edificações históricas e arqueológicas, a Carta de Burra ${ }^{10}$ indica alguns procedimentos que devem ser considerados no processo.

Os procedimentos básicos envolvem: a conservação do bem; o seu resgate e reconstrução; a restauração e a adaptação do mesmo. Podemos acrescentar a estes itens, a devolução à comunidade do bem, resgatado, reconstruído, restaurado e adaptado a um uso compatível à sua vocação cultural.

O cruzamento das informações arqueológicas com as arquitetônicas, norteou a formulação das soluções de conservação e revitalização.

As estruturas existentes não se enquadram na descrição genericamente feita para as construções do litoral, como pertencente a uma arquitetura singela, construída com a única intenção de abrigo, e sem uma preocupação plástica. Ao contrário, o que tem sido evidenciado pela pesquisa arqueológica no local, e comprovado pela documentação fotográfica existente, é uma arquitetura elaborada, com sobrados, decorrente de um período econômico ligado ao comércio do arroz. Esses sobrados abrigavam armazéns no térreo e moradia no andar superior, e, de acordo com as informações bibliográficas, seguiam a tradição pombalina importada de São Paulo. Este tipo de construção associado ao Porto do Ribeira confirma a sua importância como pólo econômico regional.

A garantia da revitalização de um área é seu uso e a incorporação social do espaço, pois somente a utilização assegura a conservação.

O trabalho no sítio arqueológico Porto do Ribeira está longe de representar um estudo individual e isolado, pois está correlacionado ao entorno e à história econômica da região.

Recebido para publicação em 15 de dezembro de 2000.

(9) Em um período anterior, o processo de desfavelamento no local já havia sido realizado pela iniciativa privada, sendo que na implantação deste projeto a prefeitura é que fará o translado dos moradores para outro terreno.

(10) ICOMOS-Conselho Internacional de Monumentos e Sítios, Austrália, 1980.
A conscientização por parte da comunidade do valor do seu patrimônio arqueológico e histórico coincide com a definição da vocação da região, relacionada ao turismo ecológico e cultural.

A arqueologia histórica como meio de fornecer informação sobre o passado mais recente contribuiu para reverter o quadro de abandono e esquecimento de uma área, mostrando a sua importância no passado e no processo de desenvolvimento da cidade de Iguape, fazendo com que as antigas estruturas, repensadas e reutilizadas no presente, sejam conservadas para o futuro.

A dificuldade que a cidade de Iguape tem tido em conviver com os vestígios físicos do passado pode ser minimizada com a valorização deste e a possibilidade de sua utilização para gerar recursos econômicos para a população atual, ajudando na estruturação de uma industria turística.

\section{Agradecimento}

Gostaríamos de agradecer ao prefeito municipal de Iguape Capitão João Muniz Cabral, que acreditou na proposta e apoiou a realização deste projeto, igualando a cidade a outras que desenvolveram posições semelhantes em relação à valorização e aproveitamento do patrimônio cultural.

\author{
Maria Cristina Mineiro Scatamacchia* \\ Marcelo Pini Prestes** \\ Silvestre de Lima Neto*** \\ Sérgio Moraes**** \\ Rivaldo Pavlawski**** \\ Abel de Oliveira Rocha****
}

(*) Museu de Arqueologia e Etnologia da Universidade de São Paulo, Bolsista do CNPq.

(**) Museu de Arqueologia e Etnologia da Universidade de São Paulo. Pós-graduação em Arqueologia, Mestrado.

(***) Centro Cultural do Porto do Ribeira.

(****) Prefeitura Municipal de Iguape. 